\title{
Effects of mycophenolate mofetil on key pattern of coronary restenosis: a cascade of in vitro and ex vivo models Rainer Voisard*1, Sandra Viola ${ }^{\dagger 1}$, Verena Kaspar ${ }^{\dagger 1}$, Christian M Weber ${ }^{\dagger 1}$, Lutz von Müller ${ }^{2}$, Regine Baur ${ }^{1}$, Iris Gastrock-Balitsch ${ }^{1}$ and Vinzenz Hombach ${ }^{1}$
}

Address: ${ }^{1}$ Department of Internal Medicine II - Cardiology, Institute of Mikrobiology and Immunology, University of Ulm, Germany and ${ }^{2}$ Department of Virology, Institute of Mikrobiology and Immunology, University of Ulm, Germany

Email: Rainer Voisard* - rainer.voisard@uni-ulm.de; Sandra Viola - polar.licht@web.de; Verena Kaspar - verena.kaspar@freenet.de; Christian M Weber - christian.weber5@gmx.de; Lutz von Müller - lutz.mueller@medizin.uni-ulm.de; Regine Baur - regine.baur@medizin.uniulm.de; Iris Gastrock-Balitsch - iris.gastrock-balitsch@medizin.uni-ulm.de; Vinzenz Hombach - vinzenz.hombach@medizin.uni-ulm.de

* Corresponding author †Equal contributors

Published: 12 May 2005

BMC Cardiovascular Disorders 2005, 5:9 doi:10.1 186/147|-226I-5-9

This article is available from: http://www.biomedcentral.com/|47|-226|/5/9

(c) 2005 Voisard et al; licensee BioMed Central Ltd.

This is an Open Access article distributed under the terms of the Creative Commons Attribution License (http://creativecommons.org/licenses/by/2.0), which permits unrestricted use, distribution, and reproduction in any medium, provided the original work is properly cited.
Received: 17 December 2004

Accepted: 12 May 2005

\begin{abstract}
Background: Mycophenolate mofetil (MMF), the prodrug of mycophenolic acid (MPA), is a rationally designed immunosuppressive drug. The current study investigates the effect of MMF on key pattern of restenosis in a cascade of in vitro and ex vivo models.

Methods: Part I of the study investigated in northern blot and cytoflow studies the effect of MMF (50, 100, I50, 200, 250 , and $300 \mu \mathrm{g} / \mathrm{mL}$ ) on TNF- $\alpha$ induced expression of intercellular adhesion molecule I (ICAM-I) in human coronary endothelial cells (HCAEC) and human coronary medial smooth muscle cells (HCMSMC). Part II of the study applied a human coronary 3D model of leukocyte attack, the 3DLA-model. HCAEC and HCMSMC were cultured on both sides of a polycarbonate filters, mimicking the internal elastic membrane. Leukocyte attack (LA) was carried out by adding human monocytes (MC) on the endothelial side. The effect of MMF $(50 \mu \mathrm{g} / \mathrm{mL})$ on adhesion and chemotaxis $(0.5$, I, 2 , $3,4,6$, and $24 \mathrm{~h}$ after LA) and the effect on proliferation of co-cultured HCMSMC ( $24 \mathrm{~h}$ after LA) was studied. In part III of the study a porcine coronary organ culture model of restenosis (POC-model) was used. After ex vivo ballooning MMF $(50 \mu \mathrm{g} / \mathrm{mL})$ was added to the cultures for a period of I, 2, 3, 4, 5, 6, and 7 days. The effect on reactive cell proliferation and neointimal thickening was studied at day 7 and day 28 after ballooning.

Results: Expression of ICAM-I in northern blot and cytoflow studies was neither clearly inhibited nor stimulated after administration of MMF in the clinical relevant concentration of $50 \mu \mathrm{g} / \mathrm{mL}$. In the 3DLA-model $50 \mu \mathrm{g} / \mathrm{mL}$ of MMF caused a significant antiproliferative effect $(p<0.001)$ in co-cultured HCMSMC but had no effect on MC-adhesion and MCchemotaxis. In the ex vivo POC-model neighter reactive cell proliferation at day 7 nor neointimal hyperplasia at day 28 were significantly inhibited by MMF $(50 \mu \mathrm{g} / \mathrm{mL})$.

Conclusion: Thus, the data demonstrate a significant antiproliferative effect of clinical relevant levels of MMF (50 $\mu g /$ $\mathrm{mL}$ ) in the 3DLA-model. The antiproliferative effect was a direct antiproliferative effect that was not triggered via reduced expression of ICAM-I or via an inhibition of MC-adhesion and chemotaxis. Probably due to technical limitations (as e.g. the missing of perfusion) the antiproliferative effect of MMF $(50 \mu \mathrm{g} / \mathrm{mL})$ could not be reproduced in the coronary organ culture model. A cascade of focused in vitro and ex vivo models may help to gather informations on drug effects before large experimental studies are initiated.
\end{abstract}




\section{Background}

Stent coating with immunosuppressive or cytostatic agents are valid advances in the struggle against restenosis following coronary intervention. However these therapies are hampered by high costs, especially in the case of multivessel disease. Moreover it is not entirely clear whether restenosis is merely delayed and not inhibited [[1], review]. Consequently the intense search for a systemic approach to inhibit restenosis is required.

Restenosis is essentially characterized by migration and proliferation of smooth muscle cells and extracellular matrix accumulation. However, there is now increasing evidence for a role of inflammation in the development of restenosis. The underlying molecular mechanisms of restenosis are, in fact, most probably regulated by inflammatory mediators, such as cytokines [[2], review]. The situation resembles to a certain degree to the activation of the immune system during organ rejection. Therefore it is not surprising that immunosuppressive agents are potential candidates in the treatment of restenosis.

Mycophenolate mofetil (MMF), the prodrug of mycophenolic acid (MPA), is a rationally designed immunosuppressive drug. The active metabolite MPA is a selective, non-competitive and reversible inhibitor of inosine monophosphate dehydrogenase (IMPDH) and of the type II isoform in particular [3]. The primary mechanism of action of MPA is presumed to be anti-lymphoproliferative, a result of inhibition of inosine 5'-monophosphate dehydrogenase (IMPDH), which is required for the de novo synthesis of guanosine nucleotides which are necessary for DNA and RNA synthesis and for lymphocytes to proliferate maximally after stimulation [4]. Antiproliferative effects of MMF have been described in non-immune cells [[5], review].

In the past data of animal studies could not be transferred easily to the clinical situation due to species differences. In the current study a cascade of human in vitro models in combination with a porcine coronary ex vivo model is applied to investigate the effects of MMF on key pattern of restenosis. Unexpected or conflicting data can be analysed before large experimental studies are initiated. Furthermore attention is focused on the relation between significant inhibitory effects in vitro (SI) and maximal plasma levels in vivo (MPL), the SI/MPL-ratio [6].

Central part of the current study is a 3D human coronary transfilter co-culture model of leukocyte attack [7]. In this model the effect of MMF on monocyte (MC) adhesion and chemotaxis and reactive cell proliferation of co-cultured smooth muscle cells (SMC) are investigated. In order to obtain information on the effect of MMF on TNFalpha induced expression of adhesion molecules, the effect on expression of ICAM- 1 is studied in northern blot and cytoflow studies. Finally MMF is added in a porcine coronary organ culture model of restenosis for 1, 2, 3, 4, 5,6 , and 7 days and the effect on reactive cell proliferation and neointimal hyperplasia is investigated.

\section{Methods \\ Cell culture}

Human coronary endothelial cells (HCAEC) and human coronary smooth muscle cells (HCMSMC) were purchased at Cambrex Bio Science (Vervier, B). HCAEC were cultured in Endothelium Growth Medium (Cambrex) and identified by the typical "cobble stone" growth pattern and positive reaction against von Willebrand factor (Dakopatts). HCMSMC were grown in Smooth Muscle Cell Growth Medium (Cambrex). For identification of HCMSMC antibodies against smooth muscle $\alpha$-actin (Renner, Darmstadt, D) were used. Human MC were isolated from the residual leukocytes of single donors using MACS cell-isolation kit (Milteny Biotec $\mathrm{GmbH}$ ).

\section{Mycophenolate Mofetil}

Mycophenolate mofetil (MMF): Cellcept ${ }^{\circledR}$, Roche, Basel, $\mathrm{CH}, 0.005-500 \mu \mathrm{g} / \mathrm{mL}$, dilution: aqua ad inject., MPL: 34 $\mu \mathrm{g} / \mathrm{mL}[8]$.

\section{RNA extraction and Northern blot analysis}

For Northern blot studies of the effect of MMF/TNF- $\alpha$ treatment on expression of ICAM-1, monocultures of HCAECs and HCMSMCs were incubated with MMF (50, $100,150,200,250$, and $300 \mu \mathrm{g} / \mathrm{mL}$ ) for a period of $18 \mathrm{hrs}$. During the last 6 hrs of MMF incubation, expression of adhesion molecules was stimulated by adding of TNF- $\alpha$ $(20 \mathrm{ng} / \mathrm{mL})$. Total RNA $\left(3 \times 10^{6}\right.$ cells $)$ was isolated with RNEasy Mini Kit (Qiagen), and $10 \mu \mathrm{g}$ of RNA was used in standard Northern blot analysis with an ICAM-1 probe.

A non radioactive labelling and detection system (Amersham Biosciences Europe $\mathrm{GmbH}$, Freiburg, D) was used to detect the relative band density of ICAM-1 mRNA in comparison with TNF- $\alpha$-stimulated cells. GAPDH was used as a control. Experiments were performed in triplicate.

\section{Flow cytometry}

For flow cytometry analysis of the expression of ICAM-1 in HCAEC and HCMSMC cells were trypsinized and seeded into 6-well dishes $\left(5 \times 10^{4}\right.$ cells $)$. MMF $(50,100$, $150,200,250$, and $300 \mu \mathrm{g} / \mathrm{mL}$ ) was added to the cultures for a period of $18 \mathrm{hrs}$. During the last $6 \mathrm{hrs}$ of MMF incubation, the expression of adhesion molecules was stimulated by adding of TNF- $\alpha(20 \mathrm{ng} / \mathrm{mL})$.

After MMF/TNF- $\alpha$ treatment, cells were washed twice with phosphate-buffered saline ( $\mathrm{pH} 7.2$ ) and trypsinized. Cells were resuspended in $100 \mu \mathrm{L}$ of a FITC-conjugated 
monoclonal antibody directed against ICAM-1 (clone 84H10, Dianova Immunotech; final concentration $10 \mu \mathrm{g} /$ $\mathrm{mL}$ ) and incubated for $20 \mathrm{~min}$ at $4^{\circ} \mathrm{C}$. A total of $1 \times 10^{4}$ cells $(100 \%$ gated) were analyzed immediately with a flowcytometer (BDFACsCalibur, Durchflußzytometer Becton Dickinson, Heidelberg, D).

The effects of MMF ( $50 \mu \mathrm{g} / \mathrm{mL}-300 \mu \mathrm{g} / \mathrm{mL})$ on vitality of HCAEC and HCMSMC were analyzed with propidium iodide (Sigma-Aldrich, Taufkirchen, D).

\section{The 3DLA model}

Three-dimensional human coronary units of leukocyte attack (3DLA units) mimic the inner layers of human coronary arteries [7]. The internal elastic membrane is represented by a polycarbonate filter with a thickness of $10 \mu \mathrm{m}$ and a pore size of $5 \mu \mathrm{m}$ (Whatman, Göttingen, D). Filters were fixed in a specially designed frame and inserted in a siliconized culture dish. On both sides of the filters cell cultures were established, direct contact of the cultures was made possible through the pores of the filter.

HCMSMC were seeded on one side of the filter at a density of $2.5 \times 10^{4}$ cells $/ \mathrm{cm}^{2}$. After $24 \mathrm{~h}$ cells had attached to the surface and frame and filters were turned upside down. HCAEC were seeded on the opposite side of the filter at a density of $2.5 \times 10^{4}$ cells $/ \mathrm{cm}^{2}$. Both HCAEC- and HCMSMC-cultures were supplied with the appropriate culture medium and cultured for 14 days.

At day 14, 3DLA-units were incubated with MMF $(50 \mu \mathrm{g} /$ $\mathrm{mL}$ ) for $18 \mathrm{~h}$. During the last $6 \mathrm{~h}$ of MMF incubation, the models were treated with TNF- $\alpha(20 \mathrm{ng} / \mathrm{mL})$. For leukocyte attack, the required numbers of $\mathrm{MC}$ was calculated in relation to the relative concentration of $\mathrm{MC}$ in the full human blood [7]. $3 \times 10^{5} \mathrm{MC}$ were seeded on the endothelial side of the 3DLA-units. The effect of MMF on MC-adhesion and MC-chemotaxis was studied at $30 \mathrm{~min}$, $1,2,3,4,6$, and $24 \mathrm{~h}$ after leukocyte attack; the effect on proliferation of co-cultured HCMSMC was investigated 24 $\mathrm{h}$ after leukocyte attack. Controls were performed without MMF-treatment. [for detailed information: [7]].

\section{The porcine coronary organ culture model}

Fresh hearts of 12 pigs, ranging in age from 3 to 5 months, weighing 100 to $120 \mathrm{~kg}$, were obtained from a local slaughterhouse. In the laboratory, the left anterior descending coronary artery (LAD) was carefully prepared. Section were made at $4 \mathrm{~mm}$ intervals perpendicular to the vessel wall axis [9].

\section{Ex vivo ballooning and adding of MMF}

For ex vivo angioplasty the prepared LAD segments were placed over a $3 \mathrm{~mm}$ balloon catheter (Medtronic 14K2030E, Medtronic, Kerkrade, North Carolina, USA) and were treated with 9 bar for a period of $60 \mathrm{~s}$. After ex vivo ballooning MMF $(50 \mu \mathrm{g} / \mathrm{mL})$ was added to the cultures for a period of $1,2,3,4,5,6$, and 7 days. At each medium exchange the drug was renewed.

Cultivation and fixation of coronary organ cultures

After ballooning the segments were transferred to six-well plates (Tecnomara, Fernwald, D) and cultured in a mixture of Waymouth's MB 752/1 and Ham F12 nutrient mixture (1:1; vol/vol; Cambrex) supplemented with $15 \%$ fetal calf serum (Cambrex) at $37^{\circ} \mathrm{C}$ in $5 \%$ carbon dioxide. Organ cultures were cultured for 7 and 28 days, culture medium was exchanged every second or third day. Culture conditions for control groups were exactly the same as described for the angioplasty/MMF group.

\section{Analysis of reactive cell proliferation and neointimal thickening} The effect of MMF $(50 \mu \mathrm{g} / \mathrm{mL})$ on reactive cell proliferation and neointimal thickening was studied at day 7 and day 28 after ballooning, controls were performed with and without ballooning [for detailed information: [9]].

\section{Statistical analysis}

Data of northern blot and flow cytometry studies were presented as mean \pm S.D. Statistical significance of differences between controls and drug-treated cells was determined by paired Student's t-test. The Mann-Whitney ranksum test was used to investigate the significance of differences in the 3DLA-model and the organ culture model. Statistical significance was accepted for $P<0.05$.

\section{Results \\ Identification of cells}

In monocultures of HCAECs cells were identified by a positive reaction with antibodies directed against von Willebrand factor and by the typical "cobblestone" growth pattern in culture. Monocultures of HCMSMC exhibited the "hill and valley" growth pattern and reacted positively with antibodies against smooth muscle $\alpha$-actin.

\section{Effect of MMF on ICAM-I mRNA levels: Northern blot studies}

After TNF- $\alpha$ stimulus, band density of mRNA ICAM- 1 in HCAEC was increased 30-fold, which corresponds to a relative band density of $100 \%$ (Fig. 1). After incubation of HCAEC with MMF in concentrations of 50, 100, 150, 200, and $250 \mu \mathrm{g} / \mathrm{ml}$ expression of ICAM-1 was further increased by $23.92 \%(\mathrm{p}=0.01), 29.51 \%$ (n.s.), $75.87 \%$ (n.s.), $79 \%$ (n.s.), and $24.34 \%$ (n.s.). MMF in a concentration of $300 \mu \mathrm{g} / \mathrm{mL}$ caused an inhibition of ICAM-1 expression by $40.57 \%$ (n.s.).

In HCMSMC, band density of mRNA ICAM-1 was increased 7.5 -fold after TNF- $\alpha$-stimulus, relative band density was increased from $13.4 \%$ to $100 \%$ (n.s.). 


\section{HCAEC}

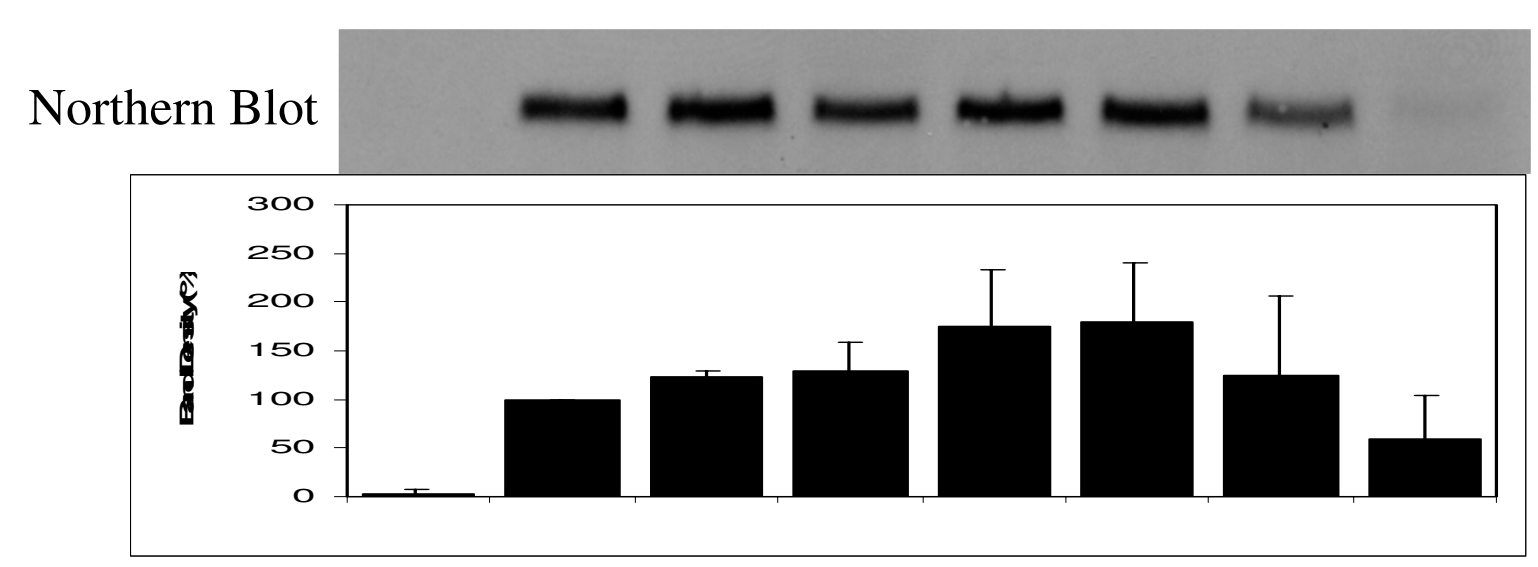

\section{HCMSMC}

\section{Northern Blot}

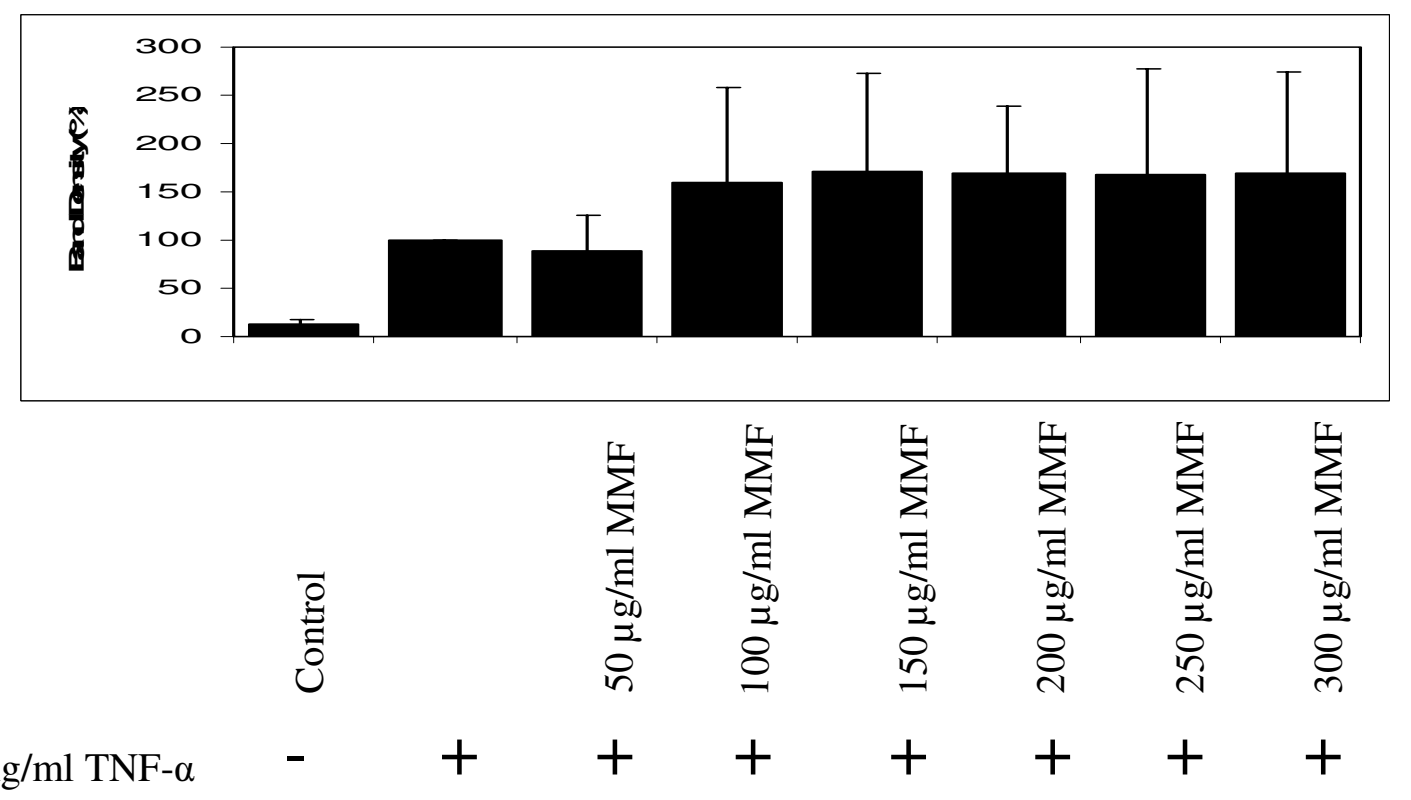

$6 \mathrm{~h} 20 \mathrm{ng} / \mathrm{mlTNF}-\alpha \quad-\quad+\quad+\quad+\quad+\quad+\quad+$

Figure I

Northern blots and relative band densities of TNF- $\alpha$-induced expression of ICAM-I mRNA after incubation of HCAECs and HCMSMCs with 50, 100, 150, 200, 250, and $300 \mu \mathrm{g} / \mathrm{mL}$ of MMF. 

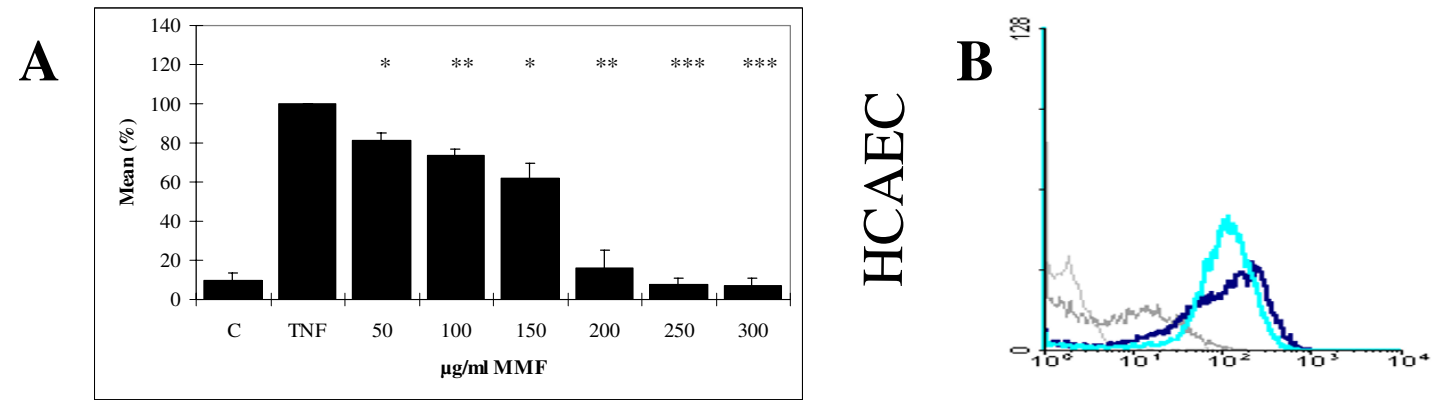

\section{$6 \mathrm{~h}$ TNF $20 \mathrm{ng} / \mathrm{ml}$}

+ $18 \mathrm{~h} \mathrm{MMF} 50$ $\mathrm{g} / \mathrm{ml}$
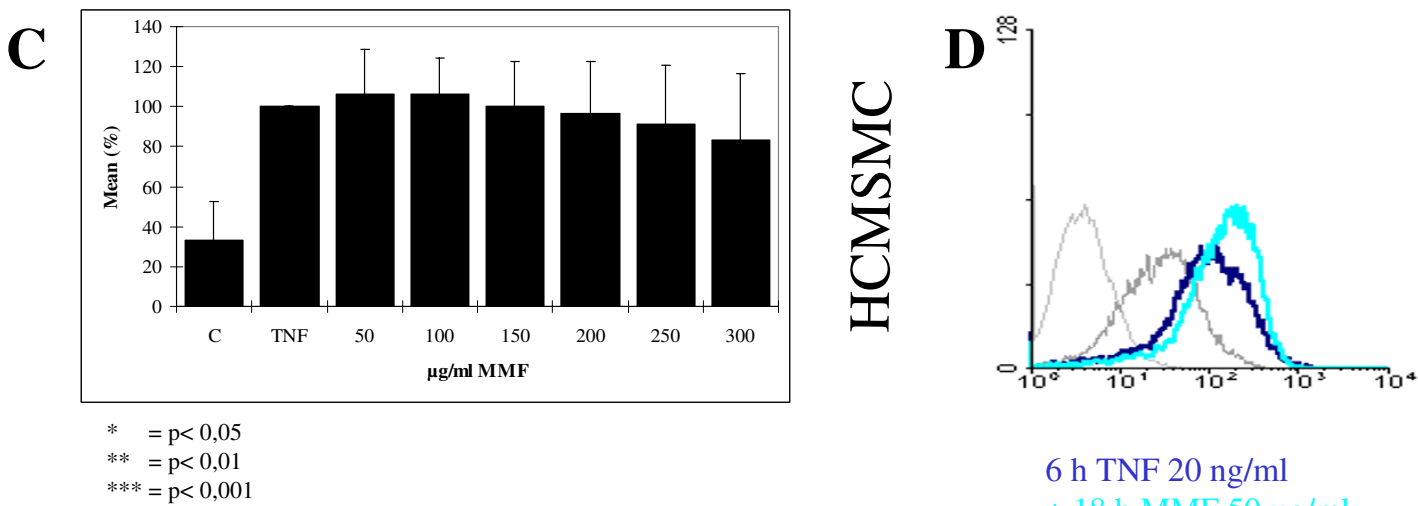

$6 \mathrm{~h}$ TNF $20 \mathrm{ng} / \mathrm{ml}$ $+18 \mathrm{~h} \mathrm{MMF} 50 \mu \mathrm{g} / \mathrm{ml}$

\section{Figure 2}

Graphics and histograms (cytoflow data) of the effect of MMF (50, 100, 150, 200, 250, and $300 \mu g / \mathrm{mL})$ on TNF- $\alpha$-induced expression of ICAM-I in HCAECs (A, B) and HCMSMCs (C, D) after $18 \mathrm{~h}$. Negative control (dotted line) and ICAM-I expression in untreated cells (grey line) are included.

Incubation with MMF in the concentration of $50 \mu \mathrm{g} / \mathrm{mL}$ caused a slight inhibitory effect on band density of mRNA ICAM-1 by $12.02 \%$ (n.s.). After incubation of HCMSMC with MMF in concentrations of 100, 150, 200, 250, and $300 \mu \mathrm{g} / \mathrm{mL}$ relative band density of ICAM-1 was increased by $59.9 \%$ (n.s.), $70.61 \%$ (n.s.), 68.7\% (n.s.), 67.8\% (n.s.), and $69.4 \%$ (n.s.).

Both in HCAEC and HCMSMC, expression of GAPDH after adding of MMF in concentrations of 50, 100, 150, 200 , and $250 \mu \mathrm{g} / \mathrm{ml}$ was identical with untreated controls.

\section{Effect of MMF on ICAM-I: Flow cytometry studies}

The effects of MMF (50, 100, 150, 200, 250, and $300 \mu \mathrm{g} /$ $\mathrm{mL}$ ) on the TNF- $\alpha$ induced expression of ICAM-1 are demonstrated in Figure 2. A dose dependent significant inhibition of ICAM-1 expression was detected in HCAEC. No significant effect was seen in HCMSMC.

In HCAEC, treatment with TNF- $\alpha$ increased the mean fluorescence levels (\%) of ICAM-1 expression 10.5-fold from $9.48 \%$ to $100.00 \%$. Incubation of HCAEC with MMF caused a dose dependent inhibition of ICAM-1 expression. After incubation with MMF in concentrations of 50, 100 , and $150 \mu \mathrm{g} / \mathrm{mL}$ expression of ICAM-1 was significantly decreased by $18.57 \%, 26.46 \%$, and $37.92 \%$ (p < $0.05, \mathrm{p}<0.01, \mathrm{p}<0.05)$. Incubation with 200, 250, and $300 \mu \mathrm{g} / \mathrm{mL}$ caused an decrease by $83.77 \%, 92.41 \%$, and $93.17 \%(\mathrm{p}<0.01, \mathrm{p}<0.001, \mathrm{p}<0.001)$. 

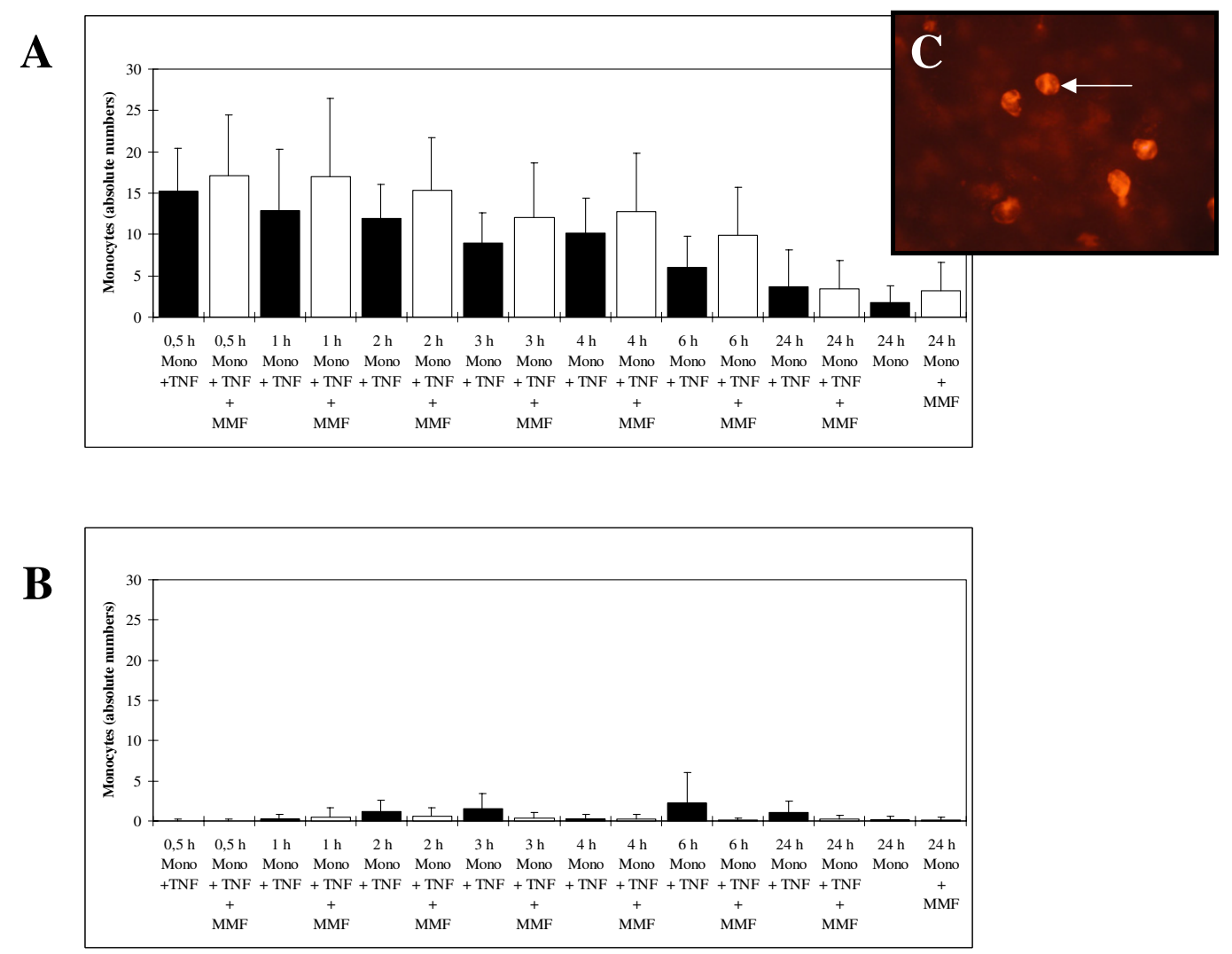

\section{Figure 3}

(A) Effect of MMF (50 $\mu \mathrm{g} / \mathrm{mL})$ on monocyte adhesion after leukocyte attack on the endothelial side of the human coronary transfilter co-culture model (3DLA units). (B) Effect of MMF $(50 \mu \mathrm{g} / \mathrm{mL})$ on monocyte chemotaxis after leukocyte attack on the endothelial side of the human coronary transfilter co-culture model (3DLA units). (C) Identification of monocytes by positive staining against CD68 (arrow).

In HCMSMC a very weak inhibition of ICAM-1 expression was detected without statistical significance. After incubation of HCMSMC with MMF in concentrations of 50,100, 150 , and $200 \mu \mathrm{g} / \mathrm{mL}$ no inhibitory effect on ICAM-1 expression was detected. MMF in concentrations of 250 and $300 \mu \mathrm{g} / \mathrm{mL}$ caused a $9.03 \%$ (n.s.) and 16.68\% (n.s.) inhibition of ICAM-1 expression.

In HCAEC no toxic effects were detected after adding of MMF in concentrations of $50 \mu \mathrm{g} / \mathrm{ml}, 100 \mu \mathrm{g} / \mathrm{ml}$, and 150 $\mu \mathrm{g} / \mathrm{ml}$, little toxic effects were found after adding of $\mathrm{MMF}$ in concentrations of $200 \mu \mathrm{g} / \mathrm{ml}, 250 \mu \mathrm{g} / \mathrm{ml}$, and $300 \mu \mathrm{g} /$ ml. In HCMSMC no toxic effects were detected after adding of MMF in concentration of $50 \mu \mathrm{g} / \mathrm{ml}-300 \mu \mathrm{g} / \mathrm{ml}$.
3DLA-Model: Effect of MMF on monocyte adhesion, chemotaxis, and proliferation of human coronary smooth muscle cells

In 3DLA units the effect of MMF in a concentration of 50 $\mu \mathrm{g} / \mathrm{mL}$ on monocyte adhesion, chemotaxis, and proliferation of HCMSMC was studied. 3DLA-units were successfully established (Fig. 3). On the endothelial side of the units one to two layers of cells were found. The superficial layer of these cells was composed of HCAEC, as identified by positive reaction with antibodies directed against von Willebrand factor. On the HCMSMC side of the units, three to five layers of cells with the typical hill and valley growth pattern were observed. 


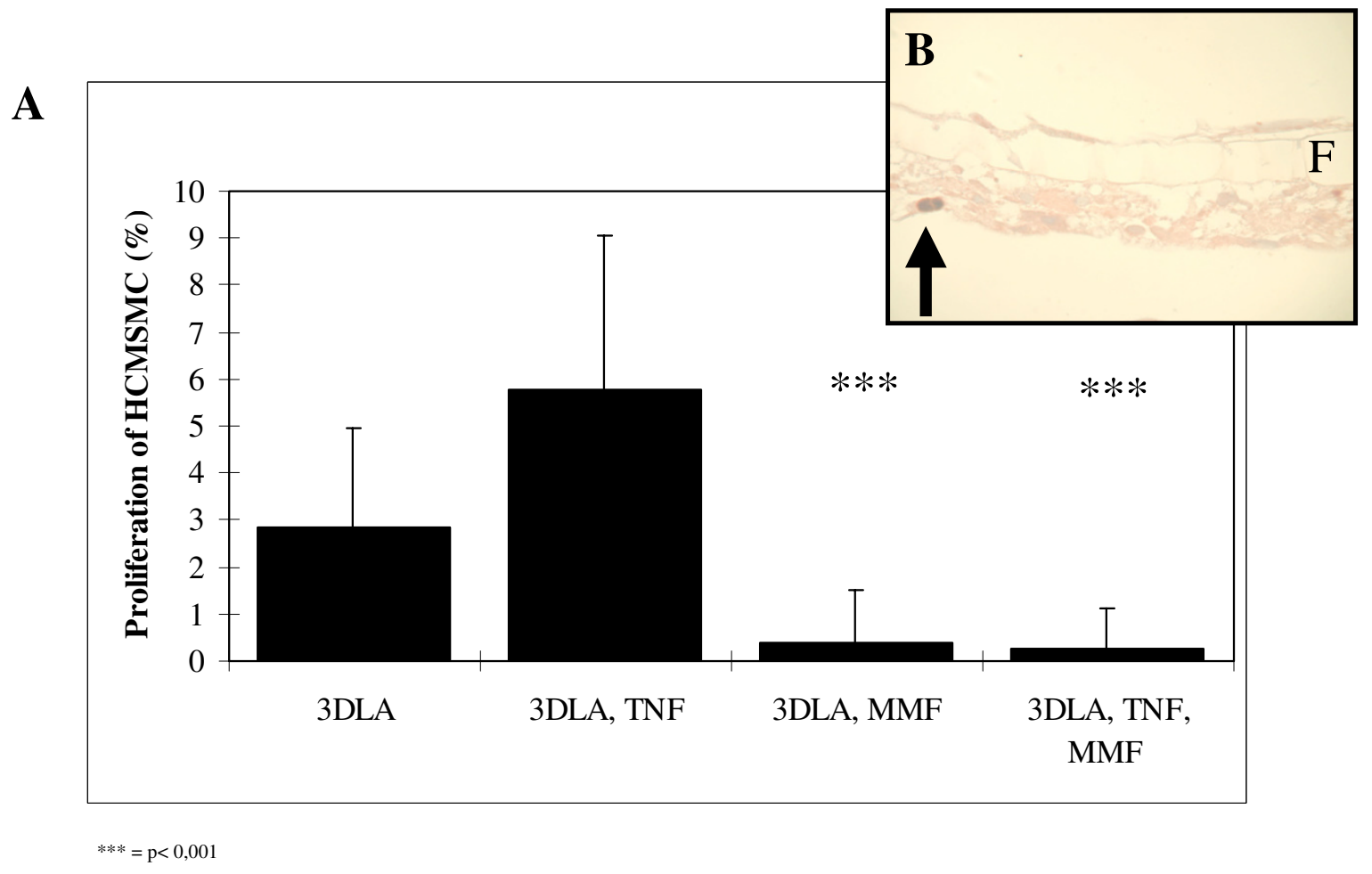

\section{Figure 4}

(A) Effect of MMF $(50 \mu \mathrm{g} / \mathrm{mL})$ on proliferative activity of co-cultured HCMSMC after leukocyte attack with monocytes on the endothelial side of TNF- $\alpha$-stimulated 3DLA units. (B) Proliferation of smooth muscle cell demonstrated by positive staining of against BrdU (arrow). F = Filter, $* * *=p<0.001$.

Human monocytes were isolated from the residual leukocytes of single donors and identified by positive reaction with antibodies directed against CD68. A 93\% purity of monocyte preparations was determined by flow cytometry.

Adhesion of MC was slightly stimulated 0.5, 1, 2, 3, 4 and $6 \mathrm{~h}$ after leukocyte attack in MMF-treated 3DLA-units (Fig. $3 \mathrm{~A}$ and $3 \mathrm{C}$ ). In comparison to 3DLA-units without MMF treatment the stimulatory effect was $12.6 \%$ (n.s.), $31.5 \%$ (p < 0.05), 29.2\% (p < 0.05), 33.2\% (n.s.), 24.9\% (n.s.), and $64,1 \%(\mathrm{p}=0.002) .24 \mathrm{~h}$ after leukocyte attack a very small inhibitory effect of MMF by $8.1 \%$ (n.s.) was detected.
Chemotaxis of $\mathrm{MC}$ from the endothelial side of the model to the HCMSMC side of the model was very little, both with and without MMF-treatment (Fig. 3B).

Proliferation of HCMSMC in the transfilter co-culture units was significantly inhibited by MMF $(50 \mu \mathrm{g} / \mathrm{ml})$ by more than $90 \%$ (Fig. $4 \mathrm{~A}$ and $4 \mathrm{~B}$ ). Proliferation of HCMSMC in the 3DLA-units after TNF- $\alpha$ stimulus was significantly stimulated by $103 \%(\mathrm{p}<0.001)$ in comparison to untreated controls. Adding of MMF in a concentration of $50 \mu \mathrm{g} / \mathrm{mL}$ significantly inhibited proliferation of HCMSMC by $95.5 \%(\mathrm{p}<0.001)$. The inhibitory effect was not influenced by TNF- $\alpha$. In the transfilter co-culture units without TNF- $\alpha$ the inhibitory effect in comparison to control was $93.4 \%(\mathrm{p}<0.001)$. 
A
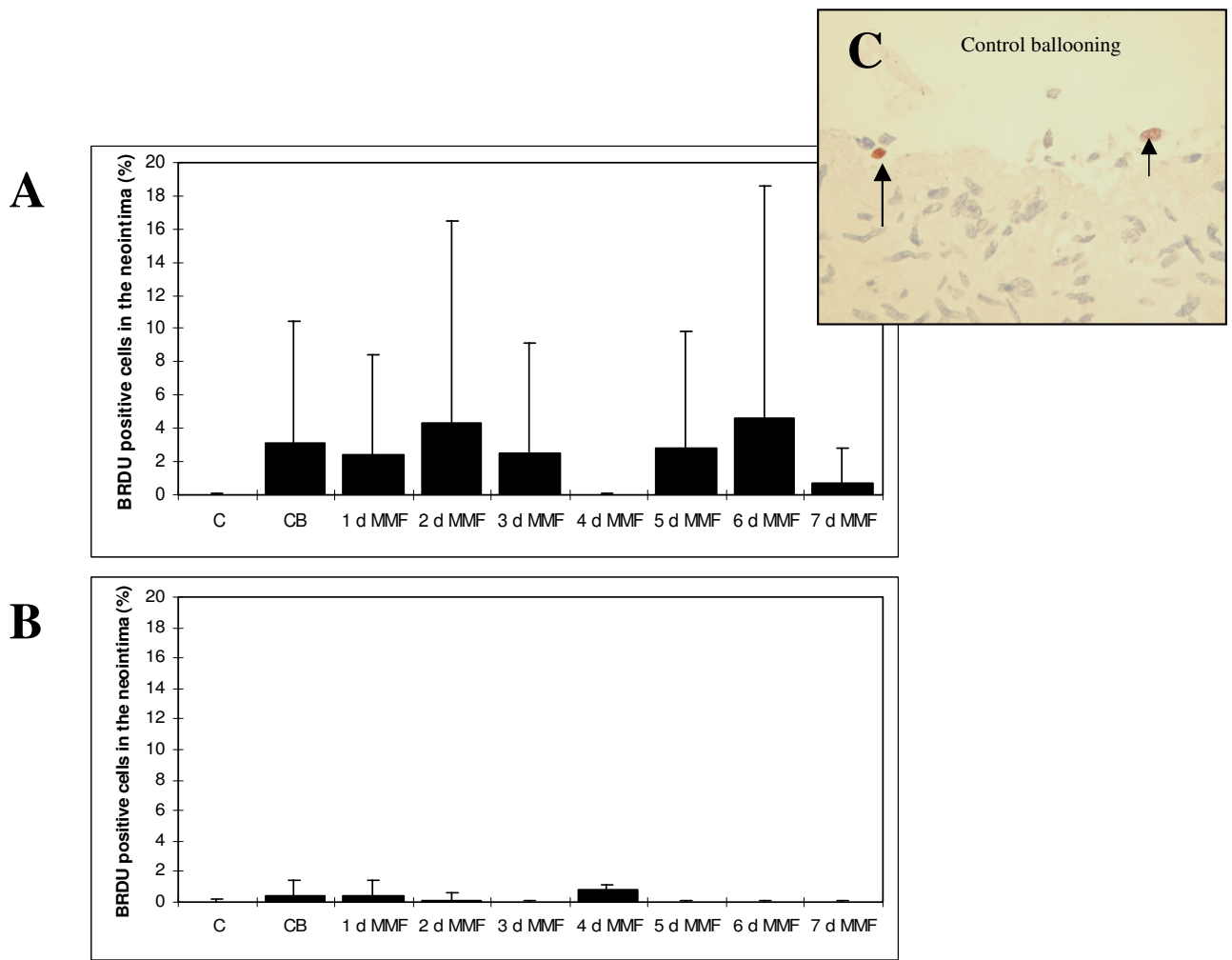

\section{Figure 5}

Effect of a I-7 days treatment with MMF $(50 \mu \mathrm{g} / \mathrm{mL})$ on reactive cell proliferation in balloon-injured porcine coronary organ cultures at day $7(\mathrm{~A})$ and day 28 (B). C = control, $C B=$ control ballooning. Positive staining against BrdU (arrow) in the ballooning control group (C).

\section{Coronary Organ Culture-Model: Effect of MMF on cell proliferation and neointimal proliferation after ex vivo ballooning}

The effects of ex vivo ballooning in the porcine organ culture model have been recently characterized by our group (9). Maximal reactive cell proliferation was detected at day 7 , maximal reactive neointimal hyperplasia was found at day 28. In the current study the effect of a 1, 2, 3, $4,5,6$, and 7 days incubation with MMF $(50 \mu \mathrm{g} / \mathrm{mL})$ on reactive cell proliferation (Fig. 5) and neointimal hyperplasia was studied 7 (Fig. 6A) and 28 days (Fig. 6B) after ex vivo ballooning. No clear inhibitory or stimulatory effect was detected.

At day 7 neointimal cell proliferation was slightly increased (n.s.) in comparison to untreated controls. Adding of MMF for 1, 3, and 5 days did not exhibit an effect on cell proliferation. A stimulatory effect was found after adding of MMF for a period of 2 and 6 days, an inhibitory effect was seen after adding of MMF for a period of 4 and 7 days. 28 days after ballooning cell proliferation in the POC-model was very low, both in untreated controls and after treatment with MMF. Almost no cell proliferation was detected in the media.

At day 7 after ex vivo ballooning neointimal hyperplasia was very low in comparison to controls. No neointimal hyperplasia was detected after adding of MMF for 1, 2, 4, and 6 days, an inhibitory effect on neointimal hyperplasia was seen after adding of MMF for a period of 3, 5, and 7 days. 28 days after ex vivo ballooning neointimal hyperplasia was increased by $809 \%$ (n.s.). Adding of MMF for a period of $1,2,3,4$, and 7 days caused an increase of neointimal thickening by $108.9 \%, 144 \%, 51.8 \%, 104.9 \%$, 


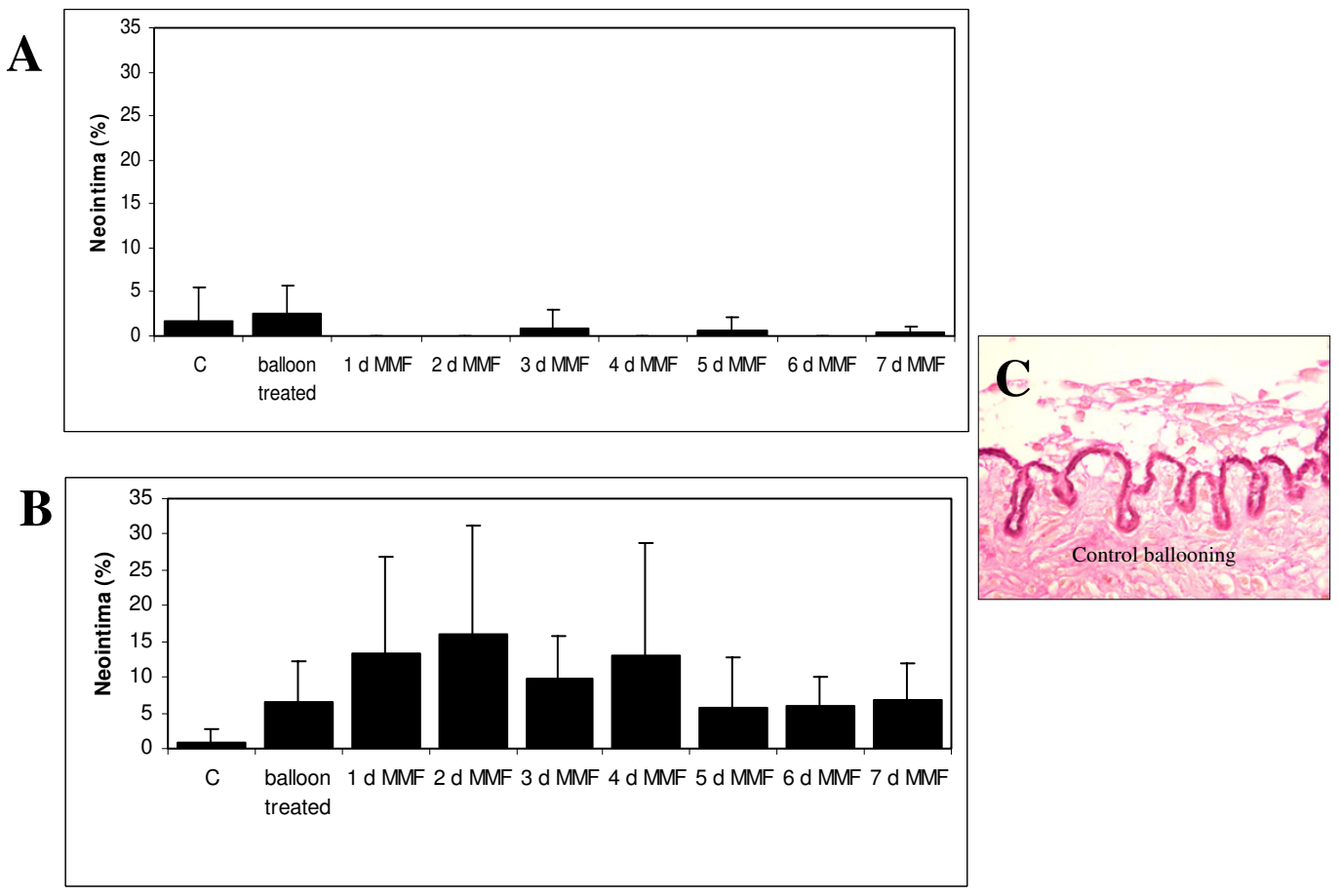

\section{Figure 6}

Effect of a I-7 days treatment with MMF $(50 \mu \mathrm{g} / \mathrm{mL})$ on reactive neointimal hyperplasia in balloon-injured porcine coronary organ cultures at day 7 and day day 28. $C=$ control, $C B=$ control ballooning. Elastica van Gieson-staining in the ballooning control group (C).

and $4.5 \%$. Adding of MMF for a period of 5 and 6 days decreased neointimal hyperplasia by $9.2 \%$ and $7.7 \%$. Due to high standard deviations statistical significance was not achieved.

\section{Discussion}

The present study employes a cascade of in vitro and ex vivo models to investigate the effect of MMF on key processes of coronary restenosis. Three basic conclusions of the study were determined. First, therapeutical concentrations of MMF exhibit a significant antiproliferative effect in HCMSMC. Second, this antiproliferative effect was not triggered via inhibition of adhesion and chemotaxis of $\mathrm{MC}$ or reduced expression of ICAM-1 on mRNA or protein levels. Third, a significant antiproliferative effect of MMF could not be reproduced in the porcine coronary ex vivo model.
MPA, a product of Penicillium fungus, was originally isolated in 1896, and shown to have anti-neoplastic, antiviral, anti-fungal and immunosuppressive activity. MMF is the semi-synthetic morpholinoethyl ester of MPA. After oral administration and absorbtion of MMF, the ester linkage is rapidly hydrolyzed by esterases to yield MPA, the active immunosuppressive agent. The bioavailability of oral MPA from MMF is $96 \%$ and the maximum of plasma concentration occurs about $2 \mathrm{~h}$ after administration [[10], review]. Over 10 years ago, MMF was first shown to prolong organ allograft survival [11]. Additional early studies demonstrated that MMF prevents acute rejection, reverses acute rejection and increases graft survival in several species and in different animal transplantation studies. Shortly thereafter, the first human renal allograft recipients were treated with MMF [[12], review]. Although many data exist on MMF in organ transplantation, data of 
the effect of MMF in experimental models of atherosclerosis and restenosis are very limited $[13,14]$.

The group of Fraser-Smith [13] demonstrated that orally administered MMF inhibits restenosis after carotid injury in a rat model and Raisanen-Sokolowski et al. [14] reported that MMF inhibits inflammation and SMC proliferation in a rat aortic allograft model. In these studies the relation between the significant in vitro respectively experimental effect (SI) and the maximal plasma level (MPL), the SI/MPL-ratio [6] was smaller than one, indicating an at least theoretical clinical relevance of the data. Recently the antiproliferative properties of MMF in nonimmune cells have been summarized in a valuable review [5]. Gregory et al. [15] reported that human aortic smooth muscle cell proliferation was significantly reduced by MMF in the presence of angiotensin II or $\beta$-FGF and Mohacsi et al. [16] demonstrated that MMF potently inhibited rat and human aortic smooth muscle cell proliferation.

In accordance with these reports the current study demonstrates a significant inhibition of HCMSMC-proliferation after incubation with $50 \mu \mathrm{g} / \mathrm{mL}$ of MMF in the 3DLAmodel. The SI/MPL-ratio [6] of 1.47 indicates that this concentration is merely slightly above systemic plasma levels of MMF. The complexity of the 3DLA-model allows studies of HCMSMC-proliferation and MC-adhesion and MC-chemotaxis in one model. Although an inhibitory effect of MMF on CD4/CD8-lymphocyte proliferation is described in the literature and an inhibitory effect on MCadhesion and chemotaxis might have been expected with reference to the clinical successes of the agent in the therapy of acute organ rejection [11], no inhibitory effect on MC-adhesion and MC-chemotaxis was detected in the 3DLA-model. An inhibitory effect on MC-adhesion and chemotaxis would have been of importance due to the fact that during the first $24 \mathrm{~h}$ after leukocyte attack monocytes seem to play a predominant role in comparison to CD4/CD8-lymphocyte attack, as recently demonstrated by our group [7]. The data indicate that the strong antiproliferative effect of MMF was not triggered via an inhibitory effect on MC.adhesion or chemotaxis.

It has been reported that MMF inhibited the induced expression of adhesion molecules on endothelial cells measured by marked antibodies and scanning fluorimetry [17]. On the other hand the group of Raab et al. [18] demonstrated that MMF in a concentration $10 \mu \mathrm{M}$ (corresponding to $3.2 \mu \mathrm{g} / \mathrm{mL}$ ) does not inhibit TNF- $\alpha$-induced stimulation of ICAM-1 in HUVEC. In the current study conflicting data are reported on mRNA and protein levels. Although in northern blot studies a stimulatory effect of MMF on TNF- $\alpha$-induced expression of ICAM- 1 was found, a dose dependent inhibitory effect was detected in flow cytometry studies. Due to the fact that littly toxic effects were found after incubation of HCAEC with MMF in concentrations of $200 \mu \mathrm{g} / \mathrm{ml}-300 \mu \mathrm{g} / \mathrm{ml}$, the decrease of ICAM-1 protein levels in HCAEC may be partially explained by these toxic effects. Clinically relevant concentrations of MMF (50 $\mu \mathrm{g} / \mathrm{mL})$ however neighter stimulated nor inhibited expression of ICAM-1. If a concentration of $50 \mu \mathrm{g} / \mathrm{mL}$ of MMF is considered the data are in accordance with the reports of Raab et al. [18]. Due to the fact that MMF $(50 \mu \mathrm{g} / \mathrm{mL})$ did not inhibit expression of ICAM-1 on mRNA- and protein levels and exhibited no effect on MC-adhesion and MC-chemotaxis, the described antiproliferative effect of MMF eighter a direct one or it was triggered via other pathways not investigated in the current study.

With the hypothesis of a direct antiproliferative effect MMF $(50 \mu \mathrm{g} / \mathrm{mL})$ was studied in the coronary porcine organ culture system of restenosis, the POC-model [9]. In the POC-model we have previously described a maximal reactive cell proliferation at day 7 and a maximal reactive neointimal hyperplasia at day 28 . In order to get information on the period of time needed to treat MMF was added for a period of $1,2,3,4,5,6$, and 7 days, the time span between angioplasty and the peak of reactive cell proliferation. In the POC-model reactive cell proliferation was inhibited after adding of MMF for a period of 4 days and 7 days, no inhibitory effect on neointimal hyperplasia was detected. These results are in accordance with the data of the experimental models applied by Fraser-Smith et al. [13] and Raisanen-Sokolowski et al. [14], describing an antiproliferative effect of an about 5-times increased concentration of MMF. Surprisingly in the current study no antiproliferative effect was detected after adding MMF for a period of 5 days and 6 days. Due to the fact that the ester linkage of MMF is rapidly hydrolysed in the plasma to MPA [10], it can be excluded that an inactive form of MMF caused the missing inhibitory effect. However high standard deviations and the absence of perfusion in the model may have contributed to the negative effect. In the presented coronary ex vivo model of restenosis $[9,19]$ the solved drug gets into contact with the adventitial side, the endothelial side, and both frontal sides of the artery segment. Therefore our group has reported earlier that the model mimics a simultaneous intra/extravascular drug administration [19]. However due to the absence of perfusion the contact between the endothelial side of the artery segments and the culture medium is limited. Limited nutrition of this area may be critical because ballooning injury and reactive cell proliferation\&neointimal hyperplasia are expected to occure predominantly in this region of the vessel wall. 


\section{Conclusion}

The current data demonstrate a significant antiproliferative effect of MMF in concentrations close to the systemic plasma level (SI/MPL-ratio: 1.47). The effect was not triggered via inhibitory effects on expression of ICAM-1 or via inhibitory effects on MC-adhesion and MC-chemotaxis. Eighter the effect was a direct antiproliferative effect or it was triggered via pathways not investigated in the present study. Probably due to technical limitations (as e.g. the missing of perfusion) the antiproliferative effect of MMF (50 $\mu \mathrm{g} / \mathrm{mL}$ ) could not be reproduced in the coronary organ culture model. A cascade of focused in vitro and ex vivo models may help to gather informations on drug effects before large experimental studies are initiated.

\section{Competing interests}

The author(s) declare that they have no competing interests.

\section{Authors' contributions}

$\mathrm{RV}, \mathrm{RB}$, and $\mathrm{VH}$ designed the study, RV wrote the manuscript. VK carried out the cytoflow studies, northern blot studies were done by RB and IGB. CMW carried out the studies with the 3DLA-model, coronary organ culture studies were done by SV.

\section{References}

I. Bhathia $V$, Bhatia R, Dhindsa M: Drug eluting stents: new era and new concerns. Postgrad Med J 2004, 80:13-18.

2. Donners MM, Daemen MJ, Cleutjens KB, Heeneman S: Inflammation and restenosis: implications for therapy. Ann Med 2003, 35:523-531.

3. Bullingham RE, Nicholls AJ, Kamm BR: Clinical pharmacokinetics of mycophenolate mofetil. Clin Pharmacokinet 1998, 34:429-455.

4. Wu JC: Mycophenolate mofetil. Molecular mechanism of action. Perspectives Drug Discovery Design 1994, 2: 185.

5. Morath C, Zeier M: Review of the antiproliferative propertries of mycophenolate mofetil in non-immune cells. Int J Clin Pharmacol Ther 2003, 4I:465-469.

6. Voisard R, Baur R, Herter T, Hombach V: Two decades of failing systemic restenosis trials: impact of the SI/MPL-ratio to characterize the clinical relevance of positive in vitro data. Perfusion 2004, I 7: 186-197.

7. Voisard R, Voglic S, Baur R, Susa M, Koenig W, Hombach V: Leukocyte attack in a 3D human coronary in-vitro model. Coron Artery Dis 200I, I 2:40I-4II.

8. Bullingham RE, Nicholls A, Hale M: Pharmacokinetics of mycophenolate mofetil (RS6 I 443). Transplant Proc I 996, 28:925-929.

9. Voisard R, Jensch V, Baur R, Höher M, Hombach V: A cornary porcine organ culture system for studies of postangioplasty cell proliferation. Coron Artery Dis 1995, 6:657-665.

10. Mele TS, Halloran P: The use of mycophenolate mofetil in transplant recipients. Immunopharmacology 2000, 47:2I5-I45.

II. Morris RE, Hoyt EG, Eugui EM, Allison AC: Prolongation of rat heart allograft survival by RS-6 I 443. Surg Forum 1989, 40:337.

12. Barten MJ, van Gelder T, Gummert JF, Boeke K, Shorthouse R, Billingham M, Morris RE: Pharmacodynamics mycophenolate Mofetil after heart transplanation: new mechanisms of action and correlations with histologic severity of graft rejection. Am J Transplant 2002, 2:719-732.

13. Fraser-Smith EB, Rosete JD, Schatzman RC: Suppression by mycophenolate mofetil of the neointimal thickening caused by vascular injury in a rat arterial stenosis model. J Pharmacol Exp Ther 1995, 275: | 204-1 208.

14. Raisanen-Sokolowsky A, Vuoristo P, Myllarniemi M, Yilmaz Sm, Kallio E, Hayry P: Mycophenolte mofetil (MMF, RS-6I443) inhibits inflammation and smooth muscle cell proliferation in rat aortic allografts. Transpl Immunol I995, 3:342-35I.

15. Gregory CR, Pratt RE, Huie P, Shorthouse R, Dzau VJ, Billingham ME, Morris RE: Effects of treatment with cyclosporine, FK 506, rapamycin, mycophenolic acid, or deoxyspergualin on vascular muscle proliferation in vitro asnd in vivo. Transplant Proc 1993, 25:770-77I.

16. Mohacsi PJ, Tuller D, Hulliger B, Wijngaard PL: Different inhibitory effects of immunosuppressive drugs on human and rat aortic smooth muscle and endothelial cell proliferation stimulated by platelet-derived growth factor or endothelial cell growth factor. J Heart Lung Transplant 1997, I 6:484-492.

17. Blaheta RA, Leckel K, Wittig B, Zenker D, Oppermann E, Harder S, Scholz M, Weber S, Encke A, Markus BH: Mycophenolate mofetil impairs transendothelial migration of allogeneic CD4 and CD8 T-cells. Transplant Proc 1999, 3 I: I 250-1252.

18. Raab M, Daxecker H, Karimi A, Markovic S, Cichna M, MarkI P, Müller $M$ : In vitro effects of mycophenolic acid on the nuleotide pool and the expression of adhesion molecules of human umbilical vein endothelial cells. Clin Chim Acta 200I, 3 I 0:89-98.

19. Voisard R, Kucharczyk E, Deininger U, Baur R, Hombach V: Simultaneous intra/extravascular administration of antiproliferative agents as a new strategy to inhibit restenosis: the peak of reactive cell proliferation as a hall mark for the duration of the treatment. BMC Cardiovascular Disorders 2002, 2:2.

\section{Pre-publication history}

The pre-publication history for this paper can be accessed here:

http://www.biomedcentral.com/1471-2261/5/9/prepub
Publish with BioMed Central and every scientist can read your work free of charge

"BioMed Central will be the most significant development for disseminating the results of biomedical research in our lifetime. "

Sir Paul Nurse, Cancer Research UK

Your research papers will be:

- available free of charge to the entire biomedical community

- peer reviewed and published immediately upon acceptance

- cited in PubMed and archived on PubMed Central

- yours - you keep the copyright

Submit your manuscript here:

http://www.biomedcentral.com/info/publishing_adv.asp
BioMedcentral 